\title{
Desafios no Desenvolvimento e na Implantação de Sistemas de Custos em Hospitais Universitários Brasileiros
}

Márcio Luiz Borinelli
Doutorado em Controladoria e Contabilidade pela Universidade de São Paulo -
USP
Professor da Faculdade de Economia, Administração e Contabilidade da
Universidade de São Paulo FEA/USP Av. Prof. Luciano Gualberto, 908. Butantã. São Paulo/SP. CEP: 05.508-010

E-mail:marciolb@usp.br

Welington Rocha Doutorado em Controladoria e Contabilidade pela Universidade de São Paulo - USP

Professor da Universidade de São Paulo - USP Av. Prof. Luciano Gualberto, 908. Butantã. São Paulo/SP. CEP: 05.508-010 E-mail:w.rocha@usp.br

Diogo Moreira Carneiro Mestrado em Controladoria e Contabilidade pela Universidade de São Paulo - USP Professor da Fundação Instituto de Pesquisas Contábeis, Atuariais e Financeiras - FIPECAFI R. Maestro Cardim, 1170. Bela Vista. São Paulo/SP. CEP: 01.323-001 E-mail: diogo.carneiro@gmail.com

\begin{abstract}
Alexandre dos Santos Silva Mestrado em Controladoria e Contabilidade pela Universidade de São Paulo - USP Analista Judiciário - Apoio Especializado Contadoria, Chefe da Seção de Análise de Custos, Conselho da Justiça Federal - CJF SCES - Setor de Clubes Esportivos Sul, Trecho 3 - Polo 8 - Lote 9. Brasília/DF. CEP: 70.200-003 E-mail: alexandredossantossilva@gmail.com
\end{abstract}

\section{RESUMO}

Os hospitais universitários brasileiros, centros de formação de profissionais e prestadores de assistência à saúde da população, passaram por grave crise em meados da década de 2000 que comprometeu o seu funcionamento. A recuperação dessas entidades envolveu a adoção de um conjunto de medidas de modernização de gestão. Nesse contexto, este trabalho teve por objetivo identificar as causas dos principais desafios enfrentados na concepção, desenvolvimento e implantação de sistemas de custos em hospitais universitários brasileiros e explorar possíveis alternativas para solucioná-los. O método de pesquisa empregado foi a pesquisa-ação, dividida em cinco etapas: (i) elaboração do projeto básico, (ii) diagnóstico, que envolveu 
Desafios no Desenvolvimento e na Implantação de Sistemas de Custos em Hospitais Universitários Brasileiros

Márcio Luiz Borinelli, Welington Rocha, Diogo Moreira Carneiro, Alexandre dos Santos Silva

observação direta, investigações em campo e entrevistas semiestruturadas como estratégias de coleta de dados, (iii) desenvolvimento do modelo conceitual; (iv) desenvolvimento operacional do sistema de custos e (v) implantação. As cinco etapas ocorreram ao longo de cinco anos na segunda década dos anos 2000, sendo que a amostra foi composta por hospitais universitários localizados em todas as cinco regiões brasileiras. Os resultados revelaram que tais desafios, entraves e percalços podem ser resumidos em cinco categorias: características organizacionais e do processo de gestão; aspectos legais e normativos inerentes ao setor público; diversidade de porte e de níveis de complexidade dos hospitais; diversidade de objetos de custeio e de propósitos de uso das informações; e escala de prioridades da área de tecnologia de informação. Esses resultados podem melhorar o conhecimento sobre o tema e auxiliar profissionais envolvidos em projetos desta natureza a se precaver sobre esses desafios e dificuldades.

Palavras-chave: Sistemas de Custos. Setor Público. Hospitais Universitários. Desafios.

\section{Challenges in the Development and Implementation of Cost System in University Hospitals Brazilian}

\section{ABSTRACT}

Brazilian university hospitals, training centers for professionals and healthcare workers, experienced a severe crisis in the mid-2000s, which even compromised their functioning. The recovery of these entities involved the adoption of a set of management modernization measures in order to ensure and improve their strategic role. In this context, this study aims at identifying the reasons of the main challenges faced in the design, development and implementation of cost systems in Brazilian university hospitals and explore possible alternatives to solve them. The research method employed was action research, divided into five stages: (i) elaboration of the basic project, (ii) diagnosis, which involved direct observation, field research and semistructured interviews as data collection strategies, (iii) development of the conceptual model; (iv) operational development of the cost system and (v) implementation. The five stages occurred over five years in the second decade of the 2000s, and the sample consisted of university hospitals located in all five Brazilian regions. The results revealed that such challenges, obstacles and mishaps can be summarized in five categories: organizational characteristics and management process; legal and normative aspects inherent to the public sector; diversity of size and levels of complexity of hospitals; diversity of objects of costing and purposes of use of information; and scale of priorities in the area of information technology. These results can improve the theoretical knowledge on the subject and help professionals involved in projects of this nature to be aware of these challenges and difficulties.

Keywords: Cost systems. Public Sector. University Hospitals. Challenges. 
Desafios no Desenvolvimento e na Implantação de Sistemas de Custos em Hospitais Universitários Brasileiros

Márcio Luiz Borinelli, Welington Rocha, Diogo Moreira Carneiro, Alexandre dos Santos Silva

\section{Desafíos en el Desarrollo y Implementación de Sistema de Costos en Hospitales Universitarios Brasileños}

\section{RESUMEN}

Los hospitales universitarios brasileños, centros de formación para profesionales y trabajadores de la salud, experimentaron una grave crisis a mediados de la década de 2000, que incluso comprometió su funcionamiento. La recuperación de esas entidades implicó la adopción de un conjunto de medidas de modernización de la gestión con el fin de asegurar y mejorar su papel estratégico. En este sentido, este trabajo tiene como objetivo identificar las causas de los principales desafíos enfrentados en la concepción, desarrollo e implantación de sistemas de costes en los hospitales universitarios brasileños y explorar posibles alternativas para resolverlos. El método de investigación empleado fue la investigación-acción, dividida en cinco etapas: i) elaboración del proyecto básico, (ii) diagnóstico, que implicó observación directa, investigaciones de campo y entrevistas semi estructuradas como estrategias de recolección de datos, (iii) desarrollo del modelo conceptual; (iv) desarrollo operativo del sistema de costes y (v) implantación. Las cinco etapas ocurrieron durante cinco años en la segunda década de los años 2000, y la muestra consistió en hospitales universitarios ubicados en las cinco regiones brasileñas. Los resultados revelaron que tales desafíos, obstáculos y percances pueden resumirse en cinco categorías: características organizacionales y proceso de gestión; aspectos jurídicos y normativos inherentes al sector público; diversidad de tamaños y niveles de complejidad de los hospitales; diversidad de objetos de cálculo de costes y propósitos de uso de las informaciones; y escala de prioridades en el ámbito de la tecnología de información. Esos resultados pueden mejorar lo conocimiento teórico sobre el tema y ayudar a los profesionales involucrados en proyectos de esta naturaleza a precaverse de estos desafíos y dificultades.

Palabras clave: Sistemas de costes. Sector Público. Hospitales Universitarios. Desafíos.

\section{INTRODUÇÃO}

Os hospitais universitários brasileiros (HUB) possuem múltiplas finalidades, pois são considerados Hospitais de Ensino, ou seja, neles se desenvolvem atividades de ensino, pesquisa e extensão para capacitar profissionais da área da saúde, mas há também a prestação de serviços de assistência à saúde da população local (Sodré, Littike, Drago, \& Perim, 2013). Nesse sentido, esses hospitais estão vinculados ao Ministério da Educação ou às Secretarias de Estado da Educação, por serem centros 
Desafios no Desenvolvimento e na Implantação de Sistemas de Custos em Hospitais Universitários Brasileiros

Márcio Luiz Borinelli, Welington Rocha, Diogo Moreira Carneiro, Alexandre dos Santos Silva

de formação, e ao Ministério da Saúde (MS) ou às Secretarias de Estado da Saúde, uma vez que os "hospitais universitários e de ensino integram-se ao Sistema Único de Saúde (SUS), mediante convênio, preservada a sua autonomia administrativa" de acordo com o art. 45 da Lei $n^{\circ} 8.080$, de 19 de setembro de 1990.

Apesar disso, em meados da década de 2000, uma crise passou a assolar essas entidades, comprometendo suas atividades fim. Essa crise permeava, dentre outros, os seguintes aspectos: "processos de financiamento, gestão de pessoal, prestação de serviços assistenciais - SUS, gestão tecnológica, pesquisa, desenvolvimento de sistemas de informações, avaliação de desempenho" (Barros, Silva, Souza, Melo, \& Taveira, 2013). Por essa razão, como um exemplo para se mitigar esta crise, instituiuse o Programa de Reestruturação dos Hospitais Universitários Federais (REHUF), no âmbito do SUS, por meio do Decreto $n^{\circ}$ 7.082, de 27 de janeiro de 2010, regulamentado pela Portaria Interministerial $n^{\circ} 883$, de 5 de julho de 2010, que dispõe principalmente sobre o financiamento compartilhado dos hospitais universitários e sobre pactuação de metas.

Ocorre que grande parte do setor público brasileiro é carente de informações gerenciais e de práticas modernas de gestão, particularmente de gestão de custos. A fim de auxiliar na solução deste problema, os autores da presente pesquisa buscaram conceber e desenvolver um sistema para gestão de custos que fosse além dos esforços associados à execução e ao controle orçamentário de maneira restrita aos critérios estabelecidas por lei, prática comum na administração pública brasileira (Costa \& Miranda, 2002). A ideia foi desenvolver um sistema que proporcionasse informações de custos adequadas para planejamento, controle, avaliação de desempenho e tomada de decisões, tanto no âmbito de cada hospital quanto no nível de redes de unidades hospitalares.

O projeto buscou desenvolver um sistema abrangente de custos a ser implementado em hospitais universitários brasileiros, para atender aos principais anseios de seus gestores e contemplar as peculiaridades da amostra, tanto em termos de complexidade quanto em termos regionais. O sistema deveria ser assertivo no 
Desafios no Desenvolvimento e na Implantação de Sistemas de Custos em Hospitais Universitários Brasileiros

Márcio Luiz Borinelli, Welington Rocha, Diogo Moreira Carneiro, Alexandre dos Santos Silva

fornecimento das principais informações para tomada de decisões, e simples, buscando apresentá-las de tal modo que mesmo os não familiarizados com conceitos contábileconômico-financeiros pudessem utilizá-las. Ademais, o sistema não poderia prescindir de uma metodologia robusta, amparada em sólidas bases conceituais.

No entanto, durante o desenvolvimento do projeto, inúmeros desafios, dificuldades e percalços imprevisíveis foram emergindo e colocando em risco o alcance dos seus objetivos. É nesse espectro que se delineia e se materializa a situação problema-objeto desta pesquisa, que reside na necessidade e no desafio de se investigar as causas desses empecilhos, algo não contemplado na literatura que trata desse tema, especificamente nesse setor.

Diante desse contexto, levantou-se o seguinte questionamento que orienta 0 presente artigo: quais são as causas dos empecilhos e desafios de se conceber, desenvolver e implantar sistemas de informações de custos em hospitais universitários brasileiros e como solucioná-los?

Assim, este trabalho, conduzido por meio de uma pesquisa-ação, tem o objetivo de identificar as causas dos desafios, entraves e percalços enfrentados na concepção, desenvolvimento e implantação de sistemas de informações de custos para hospitais universitários brasileiros e as alternativas de ação para superá-los.

A importância desta pesquisa se justifica pelo fato de que uma das formas relevantes de financiamento desses hospitais é o repasse obtido do SUS após a prestação do serviço de assistência à saúde. Como a remuneração por serviço se dá com base na tabela SUS, cujos valores são amplamente questionados, faz-se necessário que o hospital faça o acompanhamento dos custos dos serviços prestados para que possa, se for o caso, questioná-los junto ao SUS (Barros et al, 2013; Sodré et al, 2013; Silva, Oliveira, Campos, \& Oliveira, 2015; Oliveira, 2016). Portanto, é um conhecimento necessário para a subsistência das entidades. Do ponto de vista prático, considera-se também que o conhecimento dos entraves à realização de um projeto desse vulto é de interesse dos gestores envolvidos com a administração na área da saúde e no setor público. 
Desafios no Desenvolvimento e na Implantação de Sistemas de Custos em Hospitais Universitários Brasileiros

Márcio Luiz Borinelli, Welington Rocha, Diogo Moreira Carneiro, Alexandre dos Santos Silva

Além de contribuir para com a literatura, a relevância em se identificar as causas de tais desafios, percalços e dificuldades, bem como a forma de solucioná-los, está no fato de proporcionar conhecimento a todos os atores envolvidos em empreitadas análogas a se precaverem, a fim de obterem mais eficiência, eficácia e efetividade na implantação de sistemas de custos em situações e circunstâncias comparáveis.

Assim, os achados desta pesquisa poderão contribuir para que projetos futuros semelhantes a esse possam antecipar-se a possíveis situações que inibam o sucesso do projeto, bem como saber como lidar com tais situações.

Há na literatura outros artigos que versam sobre temática semelhante, como é o caso de Bonacim e Araujo (2010), que analisam a situação do sistema de custos do Hospital das Clínicas da Faculdade de Medicina de Ribeirão Preto e avaliam a proposta de mudança de metodologia de custeio, partindo-se do custeio por absorção para o custeio baseado em atividades, por meio da metodologia do estudo de caso; Barros et al. (2013) que investigam se há sistema de custos nos hospitais universitários para subsidiar tomadas de decisão e utilizam como metodologia a pesquisa descritiva, com levantamento bibliográfico e estratégia qualitativa; Sodré et al. (2013) expõem a atuação de uma empresa pública enquanto possível novo modelo de gestão para os hospitais universitários e constroem algumas inferências quanto às consequências da adoção desse modelo; Oliveira (2016) que apresenta o processo de implantação de sistema de gestão de custos no Hospital Universitário Federal Professor Alberto Antunes, em Alagoas, tomando como base metodológica o Project Management Body of Knowledge (PMBOK). O presente artigo se diferencia dos demais por: (i) compor uma amostra de dez hospitais universitários, número significativamente maior que os demais estudos e que abrangem as cinco regiões geográficas brasileiras; (ii) utilizar como metodologia pesquisa-ação e entrevistas; e (iii) realizar um mapeamento dos desafios, percalços e dificuldades encontrados no processo de implantação de um sistema de custos e sugerir ações para solucioná-los.

O artigo organiza-se da seguinte forma: além dessa Introdução, na Seção 2 são apresentados conceitos relacionados à gestão pública e à informação de custos. $\mathrm{Na}$ 
Desafios no Desenvolvimento e na Implantação de Sistemas de Custos em Hospitais Universitários Brasileiros

Márcio Luiz Borinelli, Welington Rocha, Diogo Moreira Carneiro, Alexandre dos Santos Silva

Seção 3 são descritos os passos para condução e análise dos desafios ao desenvolvimento do sistema de custos, conduzidos por meio de pesquisa-ação. $\mathrm{Na}$ Seção 4, os dados observados são apresentados e os resultados discutidos. Por fim, são expostas as considerações finais e sugestões para futuras pesquisas (Seção 5).

\section{FUNDAMENTAÇÃO TEÓRICA}

Mudanças nos sistemas de contabilidade gerencial são influenciadas por aspectos internos e externos (Atkinson, Balakrishnan, Booth, Cote, Groot, Malmi, Roberts, Uliana, \& Wu, 1997); logo, é necessário entender o contexto e as características ambientais para se desenvolver sistemas de custos.

O desenvolvimento de sistemas de custos voltados a hospitais públicos é útil não apenas para a gestão dos próprios hospitais, mas para o setor público como um todo, na medida em que busca munir os gestores com informações para planejamento, controle e tomada de decisão.

\subsection{A Modernização da Gestão no Setor Público}

A literatura descreve o desenvolvimento da administração pública brasileira começando como um modelo de gestão denominado patrimonialismo, em que o patrimônio público geralmente se confunde com o do mandatário. Assim, passou-se para uma gestão técnica e profissional, o chamado modelo burocrático. A direção, no entanto, mira um Estado gerencial, caracterizado pela busca de eficiência, eficácia e efetividade dos resultados e avaliação de desempenho (Torres, 2004).

O estado brasileiro desenvolve ações em diversas áreas, como segurança, saúde, educação e justiça, deixando sob responsabilidade da iniciativa privada ou do terceiro setor, via concessões ou permissões, todas as ações que não são atribuição do estado ou que, reconhecidamente, serão executadas com maior eficiência e produtividade por essas entidades. Nessa linha e dentro do contexto do modelo de gestão gerencial, Sarturi (2013) explica que "A eficiência da administração pública, a 
Desafios no Desenvolvimento e na Implantação de Sistemas de Custos em Hospitais Universitários Brasileiros

Márcio Luiz Borinelli, Welington Rocha, Diogo Moreira Carneiro, Alexandre dos Santos Silva

necessidade de reduzir custos e aumentar a qualidade dos serviços públicos prestados, tendo o cidadão como beneficiário, torna-se a meta do Estado, a essência da atividade desempenhada por este".

A administração pública gerencial é caracterizada pela influência, ou até incorporação, em suas práticas, dos princípios da administração de empresas, tais como flexibilização, descentralização, avaliação de desempenho e ênfase no cliente. No entanto, a incorporação de abordagens gerenciais sofisticadas no âmbito do serviço público brasileiro é recente e ainda rara, como corroboram Costa e Miranda (2002, p. 4), no que concerne à apuração de custos no setor público: "Ao contrário do setor privado, o setor público, aqui circunscrito à administração direta, não acumula maiores experiências com sistemas que objetivem a aferição de custos. Na verdade, não existe, sequer, metodologia disponível que possibilite a sua imediata incorporação." E continuam: "O administrador público apenas está habituado a trabalhar com os conceitos de dotação e de verba orçamentária. Não há cultura instalada para aferição de custos no serviço público" (Costa \& Miranda, 2002, p. 4).

Nesse sentido, os hospitais universitários são centros de formação de recursos humanos e de desenvolvimento de tecnologia para a área de saúde, além de prestadores de serviços à população no âmbito do SUS (Ministério da Educação, n.d.). A importância das funções que estes hospitais desempenham justifica que sua atuação deva ser orientada à obtenção de maior eficácia e eficiência organizacionais, requisitos essenciais à agregação de valor às funções mencionadas. A implantação de um sistema de custos pressupõe a adoção de um conjunto de medidas no sentido de modernizar a gestão dos hospitais universitários, garantindo e aperfeiçoando o importantíssimo papel estratégico que essas entidades desempenham para o sistema de saúde do país. Para cumprir essa missão, os hospitais universitários precisam de sistemas de informações adequados, isto é, que assegurem a excelência da gestão dos recursos orçamentários, financeiros, materiais, humanos e tecnológicos à sua disposição. 
Desafios no Desenvolvimento e na Implantação de Sistemas de Custos em Hospitais Universitários Brasileiros

Márcio Luiz Borinelli, Welington Rocha, Diogo Moreira Carneiro, Alexandre dos Santos Silva

\subsection{A Importância de Informações de Custos para Gestão dos Hospitais}

A partir das pesquisas de Kaplan (1988), Johnson e Kaplan (1991), Lukka e Granlund (1996), Waller, Shapiro e Sevcik (1999), Boyd e Cox III (2002), Machado (2002), Hughes e Gjerde (2003), Jerico e Castilho (2004), Kirche e Srivastava (2005), Mugnol e Ferraz (2006), Devine, Ealey e Clock (2008), Horngren, Sundem e Stratton (2008), Toigo e Nascimento (2008), Roy, Souchoroukov (2008), Abbeele, Roodhooft e Warlop (2009), Pinzan (2013), Martins e Rocha (2015) e Martins (2018) é possível se chegar à conclusão de que os propósitos das informações de custos estão divididos em quatro grupos, conforme mostra a Figura 1 a seguir.

\begin{tabular}{|l|}
\hline A) Decisões recorrentes e com enfoque/impactos mais internos (decisões de produção) \\
\hline 1) Gestão de custos: análise, redução e racionalização \\
\hline 2) Gestão de processos \\
\hline 3) Gestão da capacidade e do overhead \\
\hline $\begin{array}{l}\text { B) Decisões recorrentes e com enfoque/impactos internos e externos (decisões de marketing e } \\
\text { de produto) }\end{array}$ \\
\hline 1) Gestão dos serviços prestados: margens, composição (mix), desenvolvimento e descontinuidade \\
\hline 2) Gestão de resultados de unidades organizacionais (déficit ou superávit) \\
\hline 3) Avaliação de desempenhos \\
\hline C) Decisões não recorrentes \\
\hline 1) Decisões de investimentos \\
\hline 2) Decisões de terceirização: produzir ou comprar ou alugar \\
\hline 3) Análise de viabilidade econômica de projetos \\
\hline D) Decisões relativas ao processo de planejamento \\
\hline 1) Planejamento e controle operacional \\
\hline 2) Planejamento e acompanhamento orçamentário \\
\hline
\end{tabular}

Figura 1. Propósitos de Uso das Informações de Custos

Fonte: Elaborado pelos autores.

Embora não seja objetivo deste trabalho discutir esses propósitos, assim como os artefatos de gestão de custos que podem prover as informações para atingi-los, são eles que direcionam, orientam e conduzem o desenvolvimento dos sistemas de custos.

Tais propósitos são aplicáveis aos hospitais universitários, pois esses:

a) possuem recursos escassos para desempenhar suas atividades e, portanto, a gestão dos custos desses recursos é imperativa;

b) desenvolvem muitos processos, necessitando da identificação dos recursos 
Desafios no Desenvolvimento e na Implantação de Sistemas de Custos em Hospitais Universitários Brasileiros

Márcio Luiz Borinelli, Welington Rocha, Diogo Moreira Carneiro, Alexandre dos Santos Silva consumidos em cada um;

c) muitas vezes não possuem capacidade suficiente para atender a demanda, precisando gerenciar a relação entre capacidade e custos;

d) oferecem diferentes serviços à população, precisando conhecer o montante de recursos consumidos em cada serviço;

e) necessitam tomar decisões sobre investimentos, descontinuidade de processos, terceirização ou internalização de atividades, dentre outras;

f) realizam processo de planejamento e orçamento, o que demanda informações de custos etc.

No que diz respeito ao uso das informações de custos especificamente em organizações de saúde, Bertó e Beulke (2012) evidenciam os seguintes propósitos:

a) função controle, enfatizando o controle de custos para sobrevivência dos hospitais e possibilidade de reinvestimento;

b) preço de venda, com tabelas de preços diferenciadas para os grupos de clientes (particulares, convênios etc.) e precificação a partir de pacotes de serviços e procedimentos negociados previamente a preços determinados;

c) gerenciamento do resultado, por meio do estudo de "preço $x$ custos $x$ volumes adicionais" em relação a horários, instalações e espaços ociosos, além do direcionamento para oportunidades de melhor retorno;

d) planejamento e elaboração do orçamento econômico-financeiro;

e) função contábil, com ênfase em estoques e apropriação de custos.

Nesse sentido, os autores analisaram e definiram os propósitos de uso da informação de custos especificamente para a área de atuação das entidades estudadas. Essas informações correspondem à terceira etapa descrita na seção Design Metodológico da Pesquisa.

\subsection{Pesquisas Prévias}

Diante de trabalhos anteriores com temática semelhante, aos quais foi feita menção já na introdução, observa-se que o estudo de Oliveira (2016) embasa sua 
Desafios no Desenvolvimento e na Implantação de Sistemas de Custos em Hospitais Universitários Brasileiros

Márcio Luiz Borinelli, Welington Rocha, Diogo Moreira Carneiro, Alexandre dos Santos Silva

metodologia no projeto desenvolvido pelos autores do presente artigo, que visou o desenvolvimento e implantação de um sistema de custeio aplicável aos diferentes hospitais universitários. Nesse sentido, o estudo de Oliveira (2016) tem escopo mais restrito, por realizar um estudo de caso em apenas um hospital universitário, qual seja o Hospital Universitário Professor Alberto Antunes, em Alagoas; não obstante, o autor também identifica dificuldades no processo de implantação.

O primeiro deles é o que o autor chama de choque de culturas organizacionais, pois, como a instituição possui diferentes regimes de contratação de funcionários (Regime Jurídico Único para servidores, Consolidação das Leis do Trabalhistas para funcionários privados e há os empregados da Fundação Universitária de Desenvolvimento de Extensão e Pesquisa), Oliveira (2016) verifica uma resistência na implantação de um modelo de gestão novo. Ademais, o autor sintetiza o conjunto de dificuldades inerentes à instituição e o conjunto de dificuldades inerentes a implantação de um sistema de custos na instituição. Assim, o autor afirma para o primeiro caso que:

Observa-se que o Hospital Universitário Professor Alberto Antunes (HUPAA) vivencia dificuldades intrínsecas e extrínsecas, principalmente, as de comunicação, devido ao volume de colaboradores e a logística adotada; diversidade de departamentos e de classes profissionais; carência de recursos; a limitação de controle mais acurado dos materiais e medicamentos; limitação de recursos financeiros; e a demanda excessiva (Oliveira, 2016, p. 135).

Quanto aos fatores que tornam complexa a gestão de custos, o autor menciona que:

A cabo deve-se levar em consideração que o hospital desenvolve concomitantemente diversificadas atividades de farmácia, hotelaria, lavanderia, manutenção, restaurante, laboratoriais de análises clínicas e patológicas, de ultrassonografia, ambulatoriais e operatórias, de radiologia e de escola, além de prestar serviços a usuários distintos que necessitam de ajuste diferenciado e individual (Oliveira, 2016). 
Desafios no Desenvolvimento e na Implantação de Sistemas de Custos em Hospitais Universitários Brasileiros

Márcio Luiz Borinelli, Welington Rocha, Diogo Moreira Carneiro, Alexandre dos Santos Silva

No que diz respeito aos diferentes regimes de contratação e a situação de funcionários que atuam em hospitais universitários federais, especificamente, Sodré et al. (2013) destaca que existe uma carência de profissionais nos hospitais universitários e que isso ocorre em função de alguns fatores, tais como: o fato do MEC não promover novos concursos para repor o quadro de funcionários; o fato do MS não se responsabilizar pelos funcionários que atuam na área de assistência; a defasagem salarial; a proibição por parte de órgãos de controle de contratação direta de funcionários; a ausência de políticas de reposição de funcionários quando da aposentadoria de parte do quadro contratado; e a taxa de adoecimento de trabalhadores que tem por consequência o seu afastamento das funções exercidas. Os autores completam afirmando que:

A insuficiência de pessoal e/ou grande rotatividade dos vínculos contribui significativamente para a ineficiência dos serviços, a consequente precariedade da instituição e a fomentação de impasses entre os próprios trabalhadores diante dos diferentes salários, benefícios e carga horária, conforme o vínculo (Sodré et al., 2013).

Outra dificuldade apresentada na literatura é a falta de comunicação entre diferentes sistemas existentes na entidade. Bonacim e Araujo (2010), ao investigarem a possibilidade de migração de um sistema de gestão de custos baseado no Método de Custeio por Absorção para o Método de Custeio ABC no Hospital das Clínicas da Faculdade de Medicina de Ribeirão Preto, relatam que uma das principais dificuldades identificadas foi a obtenção de dados contábeis e estatísticos, pois os sistemas de informação eram incompatíveis, inclusive havia áreas em que nem todos os sistemas haviam sido implementados. Além disso, as informações produzidas não eram confiáveis, o que também representou um desafio (Bonacim \& Araujo, 2010).

$\mathrm{Na}$ seção a seguir, serão apresentados os procedimentos metodológicos empregados para o desenvolvimento deste trabalho. 
Desafios no Desenvolvimento e na Implantação de Sistemas de Custos em Hospitais Universitários Brasileiros

Márcio Luiz Borinelli, Welington Rocha, Diogo Moreira Carneiro, Alexandre dos Santos Silva

\section{DESIGN METODOLÓGICO DA PESQUISA}

O trabalho caracteriza-se como pesquisa-ação, na medida em que implica uma abordagem participante dos pesquisadores ao longo de seu desenvolvimento, constituindo um ciclo de análise representado pela sequência: constatação, concepção, planejamento e execução, seguido de novas constatações que dão início a um novo ciclo, em uma repetição contínua que dá forma à pesquisa. As intervenções representam uma manipulação experimental com o intuito de resolver os problemas observados, contribuindo, com o avanço científico (Holanda \& Machado, 2010).

A flexibilidade no planejamento da pesquisa, a intervenção e o envolvimento dos pesquisadores e a recorrência entre as etapas de investigação contribuem para sua caracterização como pesquisa-ação (Gil, 1991). Gil (1991) elenca conjuntos de ações considerados como etapas da pesquisa-ação, tais como: (i) fase exploratória; (ii) definição e formulação do problema; (iii) construção de hipóteses, quando pertinente; (iv) realização de seminário; (v) seleção da amostra; (vi) coleta de dados; (vii) análise e interpretação de dados; (viii) elaboração do plano de ação; e (ix) divulgação de resultados.

Neste trabalho, que durou cinco anos ao longo da segunda década dos anos 2000, a primeira etapa consistiu na elaboração do projeto básico. Nessa etapa, definiuse também - ainda que preliminarmente - o escopo do projeto, o campo de investigação e o auxílio dos pesquisadores; a formulação do problema a que se refere o projeto (não confundir com o problema desta pesquisa, específico aos desafios enfrentados e suas causas), o alinhamento entre os diversos participantes e a seleção da amostra. Foram selecionados dez hospitais universitários que atendessem aos seguintes requisitos: (a) representassem diversidade de porte e complexidade (pequeno, médio e grande; especialidade); e (b) contemplassem as cinco regiões geográficas do país.

$\mathrm{Na}$ segunda etapa, de diagnóstico, realizaram-se visitas dos pesquisadores a todas as unidades da amostra, sendo que cada visita durou, em média, dois dias (aproximadamente 16 horas). Além da observação direta, realizaram-se investigações 
Desafios no Desenvolvimento e na Implantação de Sistemas de Custos em Hospitais Universitários Brasileiros

Márcio Luiz Borinelli, Welington Rocha, Diogo Moreira Carneiro, Alexandre dos Santos Silva

em campo e entrevistas semiestruturadas, com apoio de questionário, com diversas equipes técnicas dos hospitais. A equipe de pesquisadores era formada por cinco pessoas: três delas eram responsáveis por conduzir as entrevistas semiestruturadas com as diversas equipes de cada hospital e cada entrevista durava, em média, 60 minutos; os outros dois pesquisadores eram responsáveis por conduzir a visita técnica a todo o hospital, com duração média de duas horas, bem como organizar os cronogramas de cada visita, fazer a interface com as equipes dos hospitais, dentre outras coisas.

Os autores, com base em sua experiência em outros projetos, bem como as necessidades emanadas neste projeto, elaboraram um roteiro na forma de questionário, que foi enviado por e-mail aos respondentes; neste caso, os responsáveis pela área de custos dos hospitais. Os temas abordados no questionário são: (a) dados de identificação e informações gerais; (b) modelo, sistema e processo de gestão; (c) atendimentos e serviços prestados; (d) recursos materiais utilizados e processos de suprimentos, de controle e de uso; (e) atividades de apoio à prestação dos serviços; (f) controladoria; (g) função financeira; (h) outros serviços administrativos; e (i) sistemas de informações. Os entrevistados ocupavam diferentes cargos, como: gerente administrativo, superintendente, chefe do setor de orçamento e finanças, chefe de contabilidade, contador, médicos, dentre outras atribuições. O número de pessoas que participava das entrevistas dependia da estrutura de cada hospital, bem como da disponibilidade dos envolvidos.

$\mathrm{Na}$ terceira etapa, a partir de análise de conteúdo dos dados coletados nas visitas (entrevistas e observação), houve o desenvolvimento do modelo conceitual do sistema de custos. Nessa análise, levou-se em conta uma sumarização dos principais elementos presentes no grupo da amostra pesquisada: estrutura, necessidade de informações, propósitos de uso, sistemas atuais implementados, capacidade da equipe local para "tocar" o sistema de custos, dentre outros aspectos. O produto dessa etapa resultou na concepção do modelo conceitual do sistema para fundamentar os dados (inputs) que deveriam alimentar os diversos módulos do sistema, os algoritmos que 
Desafios no Desenvolvimento e na Implantação de Sistemas de Custos em Hospitais Universitários Brasileiros

Márcio Luiz Borinelli, Welington Rocha, Diogo Moreira Carneiro, Alexandre dos Santos Silva

seriam utilizados para processar os dados captados e os produtos (outputs) do sistema de custos, ou seja, as informações que seriam geradas pelo sistema.

A saber, definiram-se nessa etapa os recursos, os propósitos de uso e as entidades objeto de custeio a serem contempladas pelo sistema de custos, além dos métodos, critérios, forma de atribuição de custos e relatórios a serem desenvolvidos.

$\mathrm{Na}$ etapa quatro trabalhou-se no desenvolvimento operacional do sistema, ou seja, na materialização do modelo conceitual na plataforma tecnológica. Inclui a análise do ambiente tecnológico, para identificar a fonte dos dados necessários ao funcionamento do sistema, bem como as relações entre os diversos sistemas, além do desenvolvimento do sistema de custos propriamente dito. Tal desenvolvimento levou em conta os recursos humanos e tecnológicos disponíveis, além da interação com os usuários na elaboração, na realização de ajustes e na validação do sistema.

A implantação do sistema nas unidades da amostra seria a próxima etapa, colocando-o em funcionamento. No entanto, isso não foi possível, e a implantação nos hospitais ficou comprometida - ao menos da forma como concebido inicialmente. Este trabalho apresenta, na próxima seção, parte dos motivos para aquele desfecho.

A fase final do projeto consistiria no treinamento, a qual não foi realizada de maneira efetiva. Destinava-se a capacitar os colaboradores afetados pelo projeto, tanto em aspectos conceituais relacionados à gestão de custos, quanto ao funcionamento operacional do sistema, apresentando suas funcionalidades e ferramentas de apoio à gestão. Também na seção seguinte serão exploradas as razões para a não realização desta etapa.

Em cada uma das etapas da pesquisa um conjunto de relatórios foi apresentado às instituições estudadas. Assim, para atingir o objetivo proposto e responder à questão desta pesquisa, os pesquisadores buscaram identificar em cada relatório os pontos sinalizados como: dificuldades, desafios, entraves, pontos de atenção, questões a resolver etc. A partir desses pontos os desafios foram identificados, segregados e analisados e suas causas investigadas. Os resultados são apresentados a seguir. 
Desafios no Desenvolvimento e na Implantação de Sistemas de Custos em Hospitais Universitários Brasileiros

Márcio Luiz Borinelli, Welington Rocha, Diogo Moreira Carneiro, Alexandre dos Santos Silva

\section{APRESENTAÇÃO E DISCUSSÃO DOS RESULTADOS}

O desenvolvimento de um sistema de gestão de custos se mostrou um anseio valorizado pela maior parte dos gestores das unidades visitadas ao longo do projeto; todos demonstraram entusiasmo em participar. $\mathrm{Na}$ amostra selecionada se encontram unidades em diferentes graus de maturidade em termos de gestão e utilização de informações de custos. Somente uma unidade apresentou uma sistemática recorrente e consistente de cálculo e utilização de informações de custos.

Apesar da participação de todas as unidades selecionadas, o projeto não evoluiu conforme o plano inicial e os trabalhos ocorreram de forma muito diferente da prevista. A razão disso foram inúmeros desafios que surgiram ao longo do percurso, desafios que são descritos a seguir e que inviabilizaram em larga medida a execução do projeto em sua totalidade.

Os entraves estão segregados em grupos, de acordo com sua natureza, a saber: (a) características organizacionais e de gestão; (b) questões legais e normativas pertinentes ao setor público; (c) aspectos da gestão de custos; e (d) características da tecnologia de informações.

\subsection{Características Organizacionais e de Gestão}

Os hospitais possuem estrutura organizacional similar; por se tratar de um conjunto amplo e difuso de hospitais, ele pode ser mais ou menos representativo do seu funcionamento. Em diversos casos, apesar de existir uma estrutura hierárquica formal padronizada recomendada a este tipo de organização, tal estrutura ainda não estava institucionalizada.

A distinção entre a estrutura organizacional formal e a informal é mais presente quando se trata da relação entre o hospital e sua respectiva universidade, pois, apesar de serem duas instituições diferentes, nota-se que a segregação não ocorre na prática. Essa questão representa um desafio ao desenvolvimento de sistemas de custos, na medida em que os recursos considerados para o modelo de custeio encontram-se 
Desafios no Desenvolvimento e na Implantação de Sistemas de Custos em Hospitais Universitários Brasileiros

Márcio Luiz Borinelli, Welington Rocha, Diogo Moreira Carneiro, Alexandre dos Santos Silva

associados a outras instituições que não o hospital. Essa situação faz surgir uma figura não muito comum em termos de sistemas de custos: os custos que não são gastos bem como a situação inversa: os gastos que não são custos.

Custos são recursos utilizados ou consumidos para geração de bens e serviços (Martins \& Rocha, 2015; Martins, 2018). Os hospitais objeto do estudo utilizam alguns recursos que não representam gasto efetivo para eles, por não estarem formalmente vinculados às unidades. Isso acontece no caso de profissionais que prestam serviços ao hospital, mas são ligados à universidade (professores, residentes, alunos e colaboradores em geral); edifícios e instalações cedidas; sistemas de informação de propriedade da universidade ou outros órgãos; contratos de serviços de responsabilidade da universidade utilizados também pelo hospital etc. Essa situação não se restringe à relação dos hospitais com as respectivas universidades, mas também com outras entidades, como governos municipais, estaduais e federais, organizações sociais, fundações, dentre outros.

Por outro lado, existem gastos dos hospitais que não fazem parte de seus custos, ou seja, não representam recursos consumidos para prestação de seus serviços. Isso pode ocorrer com profissionais e instalações cedidas, materiais e medicamentos repassados ou emprestados etc.

O desenvolvimento de um sistema de custos sob tais circunstâncias representa um desafio. Diferentemente do que costuma ser apresentado na literatura, em que os custos de uma entidade representam seus próprios gastos, no caso em tela essa relação é nebulosa sendo necessário definir com clareza o que se pretende representar e de que maneira serão atribuídos valores econômicos aos termos que se pretende mensurar. Um entrave para registrar custos que não são gastos é mensurar adequadamente esses recursos, haja vista que os dados monetários, o controle e o pagamento desses itens geralmente não ocorrem no hospital, mas em outras instituições.

Para resolver esse problema se buscou parceria com outros órgãos visando à obtenção dos dados necessários à operacionalização do sistema de custos. Por 
Desafios no Desenvolvimento e na Implantação de Sistemas de Custos em Hospitais Universitários Brasileiros

Márcio Luiz Borinelli, Welington Rocha, Diogo Moreira Carneiro, Alexandre dos Santos Silva

exemplo, em alguns casos foi necessário buscar parceria com os órgãos públicos de origem dos servidores cedidos aos hospitais universitários para obtenção das informações de gastos com a folha de pagamento. Uma aproximação com os sistemas de informações das universidades também foi necessária para se conhecer os valores de outros recursos utilizados pelo hospital.

Além da estrutura organizacional e seus efeitos sobre os custos, existem muitos outros aspectos relacionados à gestão que também afetaram o desenvolvimento deste projeto. De forma semelhante ao que ocorre em termos de estrutura organizacional, os hospitais universitários carecem de uniformização efetiva em termos amplos, de modo que se torna difícil conceber um único sistema que atenda a todas as unidades em todas as suas especificidades e idiossincrasias. Essa falta de uniformidade foi percebida em termos de processos, métodos e fluxos de trabalho, serviços prestados, materiais utilizados e estrutura física, sendo que cada hospital possui uma história e um conjunto de características único.

Para superar esse problema, embora a ideia do projeto consistisse em desenvolver e implantar apenas um sistema de informações de custos, não há que se falar em apenas uma forma de operar este sistema. O sistema deve possuir alternativas em termos de entrada de dados, uma vez que a existência destes dados depende de processos, controles e do nível de automatização das unidades. Além disso, o sistema também deve oferecer relatórios flexíveis que podem ser acessados de modo a atender as principais necessidades de gestão de cada unidade.

Esta solução visa resolver outro problema: a dificuldade de obtenção dos dados para alimentação do sistema de custos não se limita à falta de uniformidade entre as unidades, mas também ao tipo de gestão (mais ou menos formal) e ao nível de maturidade da organização. Em muitas unidades não foram observados controles internos e processos mapeados que permitissem a mensuração dos objetos necessários ao custeamento. Isso significa que a acurácia das informações de custos em cada unidade depende significativamente da qualidade das informações básicas de controle produzidas pelo hospital. 
Desafios no Desenvolvimento e na Implantação de Sistemas de Custos em Hospitais Universitários Brasileiros

Márcio Luiz Borinelli, Welington Rocha, Diogo Moreira Carneiro, Alexandre dos Santos Silva

Outro problema foi a falta de formação de vários colaboradores no que diz respeito a conceitos e práticas de administração, particularmente entre aqueles que devem se envolver com os processos de custos junto aos gestores das unidades organizacionais. Essa característica é observada principalmente em áreas técnicas associadas aos processos de atenção à saúde, onde ocorrem muitas decisões fundamentais à determinação dos custos hospitalares.

Apesar do interesse dos colaboradores destas áreas nos processos de custos, nota-se um certo afastamento em relação às informações produzidas nas áreas administrativas (quando existentes). As decisões são tomadas sem embasamento conceitual, principalmente quando se trata de gestão de custos. A preocupação que prevalece se limita, na maioria dos casos, aos aspectos conceituais de saúde, sem levar em conta impactos adicionais no funcionamento do hospital.

No que concerne à gestão, o setor público apresenta uma particularidade que condiciona os processos administrativos, que é a influência política na definição dos objetivos, do modelo de gestão, das práticas administrativas e dos gestores responsáveis pelos hospitais. Essa influência implica efeitos indesejados, principalmente relacionados à incerteza e à instabilidade administrativa.

$\mathrm{Na}$ medida em que estão sujeitas as definições de políticas públicas, as prioridades de cada unidade modificam-se de acordo com a alternância dos mandatários nas diversas esferas de poder. No caso em tela, houve alternância nos quadros de gestão nas organizações investigadas, e essas variações produziram modificações recorrentes nos demais aspectos de gestão (modelo de gestão, ferramentas, práticas administrativas, estratégias etc.). Um efeito nocivo dessa instabilidade é o tempo necessário para que a organização e seus colaboradores técnicos se adaptem a cada mudança de gestão. Além disso, percebe-se significativo desperdício de recursos, na medida em que iniciativas tomadas por uma gestão são frequentemente descartadas pela administração subsequente, incorrendo na perda do esforço empreendido até então.

A instabilidade nas unidades hospitalares não decorre apenas das alterações de 
Desafios no Desenvolvimento e na Implantação de Sistemas de Custos em Hospitais Universitários Brasileiros

Márcio Luiz Borinelli, Welington Rocha, Diogo Moreira Carneiro, Alexandre dos Santos Silva

caráter político. Como a maior parte dos quadros de pessoal é composta por colaboradores técnicos concursados, existe um elevado índice de rotatividade de pessoal em razão da sua aprovação em concursos promovidos por outros órgãos públicos, preferidos pelos servidores, que optam por deixar suas vagas. Dificuldade com recursos humanos que se harmoniza com o que é relatado na literatura, como nos artigos de Sodré et al. (2013) e Oliveira (2016), que evidenciam a existência de diversos regimes de trabalho dentro dos hospitais universitários brasileiros; há diferenças de cargos, salários, benefícios e outros direitos; mas também há carência de funcionários, pela impossibilidade de se promover novos concursos com a frequência que seria necessária e há múltiplas atribuições que um colaborador pode exercer, pois alguns atuam tanto na universidade quanto no hospital.

Outro desafio identificado foi a ausência de processos razoavelmente organizados e a insuficiência (ou inexistência) de registros ou informações sistemáticas e acuradas para uso gerencial, tais como registro de uso ou dispensação de materiais e medicamentos, controle de entregas e atividades das unidades organizacionais, registro e controle da atuação dos colaboradores e muitos outros controles e registros importantes para operacionalizar um sistema de custos. Desafio semelhante foi identificado por Bonacim e Araujo (2010), que observaram a falta de integração entre os diversos sistemas de informação do hospital universitário que serviu de objeto de estudo.

A Figura 2 traz um resumo dos principais desafios encontrados nessa primeira categoria, suas características relevantes e as ações recomendadas para superá-los. 
Desafios no Desenvolvimento e na Implantação de Sistemas de Custos em Hospitais Universitários Brasileiros

Márcio Luiz Borinelli, Welington Rocha, Diogo Moreira Carneiro, Alexandre dos Santos Silva

\begin{tabular}{|c|c|c|c|}
\hline & Desafios & Características & Ações \\
\hline 1 & $\begin{array}{l}\text { Estrutura } \\
\text { organizacional }\end{array}$ & $\begin{array}{l}\text { Organogramas similares; estruturas } \\
\text { não institucionalizadas; na prática, } \\
\text { padrões diferentes do formal; } \\
\text { segregação entre hospital e } \\
\text { universidade. }\end{array}$ & $\begin{array}{l}\text { Deixar o sistema flexível para } \\
\text { refletir a realidade físico- } \\
\text { operacional. }\end{array}$ \\
\hline 2 & $\begin{array}{l}\text { Custos que não são } \\
\text { gastos e gastos que } \\
\text { não são custos }\end{array}$ & $\begin{array}{c}\text { Local de consumo dos recursos } \\
\text { diferente do local de registro e } \\
\text { desembolso dos valores de tais } \\
\text { recursos. }\end{array}$ & $\begin{array}{c}\text { Definir o que se pretende } \\
\text { representar e como serão atribuídos } \\
\text { valores econômicos aos termos a } \\
\text { serem mensurados; parceria para } \\
\text { obtenção de dados e informações } \\
\text { necessárias. }\end{array}$ \\
\hline 3 & $\begin{array}{l}\text { Falta de uniformização } \\
\text { das unidades }\end{array}$ & $\begin{array}{c}\text { Dificuldade em se conceber um único } \\
\text { sistema que atenda a todas as } \\
\text { unidades em todas as suas } \\
\text { especificidades e idiossincrasias. }\end{array}$ & $\begin{array}{c}\text { Conceber um sistema com } \\
\text { diferentes formas de entradas de } \\
\text { dados e capaz de gerar relatórios } \\
\text { (saídas) flexíveis. }\end{array}$ \\
\hline 4 & $\begin{array}{l}\text { Nível de maturidade e } \\
\text { formalização da } \\
\text { gestão }\end{array}$ & $\begin{array}{l}\text { Ausência de controles internos e } \\
\text { processos mapeados que auxiliem a } \\
\text { obtenção de dados. }\end{array}$ & $\begin{array}{l}\text { Evidenciar que a implementação do } \\
\text { sistema de custos depende da } \\
\text { resolução anterior deste ponto. }\end{array}$ \\
\hline 5 & $\begin{array}{l}\text { Falta de formação dos } \\
\text { colaboradores em } \\
\text { conceitos e práticas } \\
\text { administrativas }\end{array}$ & $\begin{array}{l}\text { Decisões tomadas sem } \\
\text { embasamento conceitual } \\
\text { (informações de custos). }\end{array}$ & $\begin{array}{l}\text { Disseminação da cultura de } \\
\text { utilização de informações. }\end{array}$ \\
\hline 6 & Influência política & $\begin{array}{c}\text { Provoca incerteza, instabilidade e } \\
\text { aumento de tempo para adaptação; } \\
\text { mudanças nas prioridades a cada } \\
\text { troca de gestão; desperdício de } \\
\text { recursos. }\end{array}$ & $\begin{array}{c}\text { Não há ação que possa ser tomada, } \\
\text { neste caso. }\end{array}$ \\
\hline 7 & $\begin{array}{l}\text { Elevada rotatividade } \\
\text { de pessoal }\end{array}$ & $\begin{array}{l}\text { Funcionários que fazem concursos } \\
\text { públicos buscando outros órgãos; } \\
\text { instabilidade nos processos. }\end{array}$ & $\begin{array}{c}\text { Não há ação que possa ser tomada, } \\
\text { neste caso. }\end{array}$ \\
\hline 8 & $\begin{array}{l}\text { Inexistência de } \\
\text { processos } \\
\text { organizados e de } \\
\text { registros ou } \\
\text { informações } \\
\text { sistemáticas } \\
\end{array}$ & $\begin{array}{l}\text { Falta de registros diversos dos itens } \\
\text { necessários ao funcionamento de um } \\
\text { sistema de custos. }\end{array}$ & $\begin{array}{l}\text { Evidenciar que a implementação do } \\
\text { sistema de custos depende da } \\
\text { resolução anterior deste ponto. }\end{array}$ \\
\hline
\end{tabular}

Figura 2. Desafios Relativos às Características Organizacionais e de Gestão

Fonte: Elaborado pelos autores.

\subsection{Questões Legais e Normativas Pertinentes ao Setor Público}

Os hospitais universitários são organizações de interesse público, pertencentes ao Estado e regidas pelo arcabouço legal destinado à gestão da coisa pública. Dessa forma, é necessário o atendimento dos requisitos legais, tanto no que diz respeito à contratação de serviços de consultoria para concepção de um sistema, quanto 
Desafios no Desenvolvimento e na Implantação de Sistemas de Custos em Hospitais Universitários Brasileiros

Márcio Luiz Borinelli, Welington Rocha, Diogo Moreira Carneiro, Alexandre dos Santos Silva

eventuais aquisições de equipamentos, sistemas operacionais ou até mesmo contratação de outros serviços relacionados à tecnologia.

No que tange ao projeto de desenvolvimento do sistema de custos, essa imposição legal representa uma severa restrição, na medida em que os termos contratuais devem ser definidos de antemão para dar andamento ao processo licitatório. No caso do desenvolvimento de um sistema de informações, essa imposição é bastante danosa, uma vez que o conjunto de fatores que determinará o trabalho só será efetivamente conhecido conforme o desdobramento das atividades necessárias à sua execução, principalmente os elementos de natureza tecnológica.

As restrições legais afetaram o projeto em ao menos três aspectos: em primeiro lugar, a estimativa de horas necessárias à sua realização contém alguma imprecisão, principalmente por conta da diversidade entre as unidades, das particularidades do setor de saúde e do ambiente hospitalar, e das diversas interações necessárias com as equipes de trabalho, tanto profissionais da área de saúde dos hospitais quanto profissionais de tecnologia de informação responsáveis pela operacionalização do sistema, considerando os diversos sistemas de informações que devem se relacionar e integrar com o sistema de custos.

A impossibilidade de se estimar com precisão os detalhes do projeto dificultam a definição de preços e prazos para sua realização. Sua execução em módulos, ou de acordo com termos mais flexíveis, seria mais adequada a um projeto dessa natureza. Porém, o processo de licitação dificulta essa abordagem, ainda mais por se tratar de um tipo de serviço cuja competência técnica pode afetar severamente a qualidade do resultado final. Assim, existem algumas medidas para flexibilizar as rigorosas exigências legais, como a inexigibilidade de licitação por capacidade técnica (notório saber); porém, outras restrições se mostram incontornáveis.

O segundo entrave decorrente da legislação refere-se à aquisição de elementos adicionais ao projeto, como soluções tecnológicas adequadas ao sistema de custos. A adoção de outras soluções que não aquelas preconizadas no projeto inicial implicam novos processos de contratação, tornando necessária nova licitação, cujo resultado 
Desafios no Desenvolvimento e na Implantação de Sistemas de Custos em Hospitais Universitários Brasileiros Márcio Luiz Borinelli, Welington Rocha, Diogo Moreira Carneiro, Alexandre dos Santos Silva

pode não ser aquele esperado para o bom andamento do projeto. Nos casos ora discutidos, o que se percebeu foi que suas áreas de tecnologia da informação ( $\mathrm{TI}$ ) deveriam ter sido consideradas como contratantes e corresponsáveis pelo projeto desde o início, dado seu necessário envolvimento.

Em terceiro lugar, os hospitais possuem restrições para subcontratação de serviços necessários para realização do projeto, impossibilitando a equipe responsável de agregar atividades que não estejam dentre suas especializações, tais como habilidades e recursos tecnológicos necessários para a conclusão do desenvolvimento do sistema. Tais elementos são muito específicos e difíceis de se prever no início do projeto.

Neste tópico, outro desafio identificado foi a necessidade de se garantir que aquilo que fora planejado seria efetivamente cumprido, como preconiza uma boa prática de controladoria. Nesse quesito, há de se destacar os aspectos positivos das exigências legais. $O$ fato de existir um plano inicial (anexo ao processo de contratação) com fases e prazos de entrega previamente definidos permitiu um controle rigoroso do projeto, uma vez que a cada fase era necessário um relatório para entrega do respectivo produto.

Cruz, Andrade e Figueiredo (2011), ao versarem sobre o processo de contratação de serviços de TI ou de aplicação de softwares em organizações públicas, identificaram dificuldades semelhantes. De acordo com os autores, a contratação desse tipo de serviço encontra um grave entrave no setor público, que é a necessidade de alinhamento à legislação brasileira (Cruz et al., 2011). Ao sintetizar os trabalhos de outros autores, enumeram os seguintes riscos desse tipo de contratação: 
Desafios no Desenvolvimento e na Implantação de Sistemas de Custos em Hospitais Universitários Brasileiros

Márcio Luiz Borinelli, Welington Rocha, Diogo Moreira Carneiro, Alexandre dos Santos Silva

Descontinuidade tecnológica; dificuldade com a definição do escopo dos serviços; falta de compreensão do negócio pelos contratados; dificuldade em manter a qualidade dos serviços; [...] riscos relacionados ao descumprimento da legislação de licitações e contratos da Administração Pública, que poderiam ser, por exemplo: impugnação de procedimento licitatório ou suspensão da assinatura do contrato, causando atraso na contratação [...]; suspensão ou rompimento de contratos considerados ilegais [...]; perdas orçamentárias [...]; paralisação de projetos importantes e calcados em TI [...] (Cruz et al. 2011, p. 24).

Isso demonstra que, apesar dos potenciais benefícios de se contratar e implementar serviços de TI ou aplicação de softwares, no sentido de otimizar processos e integrar informações no setor público, há que se considerar os diversos entraves existentes, principalmente no que diz respeito à legislação brasileira da época, concernente a licitações. Portanto, além das dificuldades naturais em se implantar projetos dessa natureza, como dito por Cruz et al. (2011) acerca da definição do escopo, da manutenção da qualidade do serviço, dentre outros, há também o risco de descumprimento de alguma lei ou norma, seja durante o processo de contratação ou de execução, uma vez que a legislação é restrita no que concerne ao acréscimo de novos elementos ao contrato, e que pode obrigar a entidade a romper o acordo e abandonar o projeto.

$\mathrm{Na}$ Figura 3, encontra-se o resumo dos desafios relativos às questões legais e normativas, suas características e as ações propostas para enfrentá-los. 
Desafios no Desenvolvimento e na Implantação de Sistemas de Custos em Hospitais
Universitários Brasileiros

Márcio Luiz Borinelli, Welington Rocha, Diogo Moreira Carneiro, Alexandre dos Santos Silva

\begin{tabular}{|c|c|c|c|}
\hline & Desafios & Características & Ações \\
\hline 1 & $\begin{array}{l}\text { Atendimento dos } \\
\text { requisitos determinados } \\
\text { por estrutura legal }\end{array}$ & $\begin{array}{l}\text { Os termos contratuais devem ser definidos a } \\
\text { priori (processo licitatório); o conjunto de fatores } \\
\text { que determinará o trabalho só será conhecido } \\
\text { efetivamente conforme o desdobramento das } \\
\text { atividades; por conter aspectos tecnológicos, o } \\
\text { desenvolvimento de um sistema caracteriza-se } \\
\text { pela sua natureza incerta e dinâmica, sujeita a } \\
\text { oscilações difíceis de serem estimadas com } \\
\text { precisão antes do início do projeto; dificuldade } \\
\text { de se estimar a quantidade de trabalho } \\
\text { necessária dificulta a definição do preço do } \\
\text { serviço e do prazo de realização. }\end{array}$ & $\begin{array}{l}\text { Realização do projeto em } \\
\text { módulos, ou de acordo com } \\
\text { outros termos mais flexíveis; } \\
\text { utilização de inexigibilidade de } \\
\text { licitação por capacidade técnica } \\
\text { ("notório saber"). }\end{array}$ \\
\hline 2 & $\begin{array}{l}\text { Aquisição de elementos } \\
\text { adicionais ao projeto }\end{array}$ & $\begin{array}{l}\text { A adoção de outras soluções, diferentes do } \\
\text { projeto inicial, implica novo processo e nova } \\
\text { licitação; a área de TI não ser uma das áreas } \\
\text { contratantes do projeto, a qual tinha participação } \\
\text { fundamental, haja vista que o sistema seria } \\
\text { operacionalizado na plataforma já existente; } \\
\text { envolvimento insuficiente da área de TI; a área } \\
\text { de TI não assentia a contratação de sistemas } \\
\text { externos para a acomodação do modelo } \\
\text { conceitual desenvolvido. }\end{array}$ & $\begin{array}{l}\text { A área de TI deveria ter sido } \\
\text { envolvida como contratante e } \\
\text { corresponsável pelo projeto } \\
\text { desde seu início. }\end{array}$ \\
\hline 3 & $\begin{array}{c}\text { Restrição na } \\
\text { subcontratação de } \\
\text { serviços necessários } \\
\text { para a realização do } \\
\text { projeto }\end{array}$ & $\begin{array}{c}\text { Impossibilidade de a equipe responsável agregar } \\
\text { outras atividades que não estejam dentre suas } \\
\text { especializações. }\end{array}$ & $\begin{array}{l}\text { Dimensionar a equipe adequada } \\
\text { já no projeto. }\end{array}$ \\
\hline 4 & $\begin{array}{l}\text { Necessidade de garantir } \\
\text { que o que fora } \\
\text { planejado efetivamente } \\
\text { será cumprido. }\end{array}$ & $\begin{array}{l}\text { Existência de rigoroso controle do projeto, em } \\
\text { que a cada fase era necessário um relatório para } \\
\text { entrega do respectivo produto; cada entrega } \\
\text { tinha que ser validada pelo gestor do projeto, o } \\
\text { que permitia avaliar se o projeto estava sendo } \\
\text { realizado conforme planejado. }\end{array}$ & $\begin{array}{l}\text { Exigência de um plano inicial no } \\
\text { processo de contratação com } \\
\text { fases e prazos de entrega } \\
\text { previamente definidos, bem como } \\
\text { de entregas de produtos } \\
\text { (relatórios) a cada fase. }\end{array}$ \\
\hline
\end{tabular}

Figura 3. Desafios Relativos às Questões Legais e Normativas Pertinentes ao Setor Público

Fonte: Elaborado pelos autores.

\subsection{Aspectos de Gestão de Custos}

Desenvolver um sistema de custos para um conjunto de hospitais-ensino representa um desafio pela particularidade de seus processos, caracterizados por intensiva utilização de mão de obra especializada, além de instalações e equipamentos complexos e de alto custo. Esse arranjo significa a predominância de custos indiretos, mais difíceis de se atribuir aos objetos de custeio.

Essa dificuldade alcança níveis mais elevados quando se sabe que: (a) são ofertados produtos e serviços de diversas naturezas; (b) são realizados serviços específicos relacionados à atenção à saúde, mas também serviços complementares ou 
Desafios no Desenvolvimento e na Implantação de Sistemas de Custos em Hospitais Universitários Brasileiros

Márcio Luiz Borinelli, Welington Rocha, Diogo Moreira Carneiro, Alexandre dos Santos Silva

de apoio, como hotelaria, refeições e testes laboratoriais; (c) são utilizados produtos por meio direto ou por consignação, como no caso de órteses e próteses, além de inúmeras outras atividades fundamentais para o seu correto funcionamento.

As unidades hospitalares compreendidas variam em termos de porte (pequeno, médio e grande) e nível de complexidade (baixa a alta). Dentre os hospitais investigados, há aqueles dedicados a apenas uma especialidade, como as maternidades, até unidades com inúmeros serviços, incluindo pronto atendimento e procedimentos de todos os níveis de complexidade.

As diferenças se estendem aos processos e à forma de trabalho de cada unidade, com particularidades significativas para informações de custos. Dentre os propósitos de custos apontados pelos hospitais, identificaram-se desde informações pontuais para tomada de decisões específicas (por exemplo, definir a terceirização do serviço de refeições, ou dimensionar o tamanho de uma equipe de atendimento), até informações para decisões recorrentes, tais como os custos de cada unidade organizacional segregados por elementos, com 0 intuito de racionalizar 0 comportamento dos gestores em relação aos custos sob sua responsabilidade.

As informações de custos a serem produzidas pelo sistema poderiam ser obtidas por meio de diferentes metodologias; então, coube à equipe de pesquisadores definir a que melhor se adequasse para atender aos diferentes propósitos. Muitos não puderam ser atendidos.

A metodologia de custeio levou em conta a identificação dos direcionadores de custos. Foi realizado um levantamento extensivo com os gestores das unidades organizacionais hospitalares para identificar direcionadores de custos que: (a) representassem uma relação de causa e efeito entre sua ocorrência e o consumo de recursos; e (b) pudessem ser mensurados de forma objetiva, sistemática e recorrente, de preferência em base mensal.

Optou-se por uma metodologia amparada na segregação dos custos por atividades, em sentido amplo. Não obstante, o modelo final permaneceu com algumas diferenças em relação ao Custeio Baseado em Atividades ( $A B C)$, sendo a principal 
Desafios no Desenvolvimento e na Implantação de Sistemas de Custos em Hospitais Universitários Brasileiros

Márcio Luiz Borinelli, Welington Rocha, Diogo Moreira Carneiro, Alexandre dos Santos Silva

delas a absorção de todos os custos e despesas às entidades finais objeto de custeio, mesmo aqueles cuja rastreabilidade não fosse precisa. Essa definição pelo custeio pleno, também chamado de custeio por absorção integral, foi feita para permitir a atribuição de todos os custos e despesas aos serviços ofertados, permitindo uma comparação ao faturamento obtido por tipo de objeto de custeio, particularmente no que diz respeito aos procedimentos.

Os hospitais universitários que compõem a amostra atendem ao SUS, sendo, neste caso, tomadores, não formadores de preços. Nesse sentido, a equipe entendeu que o custeio por absorção integral representaria o método de custeio mais apropriado para o conhecimento da margem por procedimento, a qual constitui-se na principal informação demandada pela maioria dos usuários consultados durante o diagnóstico.

Dentre os desafios identificados, objeto do presente estudo, está a necessidade de atender, com a máxima precisão possível, uma pluralidade de entidades objeto de custeio, haja vista as necessidades informacionais dos diversos gestores e usuários.

Outro empecilho foi a tentativa de integração do sistema de custos com o contábil. Em alguns aspectos, em alguns hospitais, não houve problemas, como na identificação dos custos de materiais e medicamentos. Já no caso da depreciação, em muitos casos os registros patrimoniais estavam desatualizados. À época estava sendo desenvolvido em alguns hospitais investigados um sistema para registrar e atualizar todos os itens do patrimônio; só após concluída tal providência seria possível fazer a integração.

Em relação às dificuldades de implementação de sistemas de custos em hospitais públicos, como dito, Oliveira (2016) descreve a complexidade das atividades desenvolvidas por esses hospitais e como isso afeta o sistema de custos, que deve ser capaz de refletir as intrincadas relações entre as entidades que compõem os custos hospitalares. Souza e Scatena (2009, p. 10), por outro lado, apontam como principais dificuldades a "cultura dos gestores, os quais, na sua maioria, ainda não se deram conta da importância das informações geradas pelo sistema de gestão de custos para o auxílio ao controle e à tomada de decisões" e a "cultura dos servidores, os quais não 
Desafios no Desenvolvimento e na Implantação de Sistemas de Custos em Hospitais Universitários Brasileiros

Márcio Luiz Borinelli, Welington Rocha, Diogo Moreira Carneiro, Alexandre dos Santos Silva

estão acostumados a realizar o registro de todas as ações, gerando assim os dados necessários à gestão de custos"; portanto, os autores identificam que o principal empecilho para a implementação é a cultura organizacional. Em complemento, Oliveira, Blanski e Silva (2015) durante o esforço de implementação de um sistema de custos em hospitais públicos, verificaram os seguintes percalços:

(i) a falta de pessoal especializado para a sua operacionalização; (ii) a inexistência de um sistema integrado de gestão que propicie as informações de forma rápida e precisa; (iii) a inexistência de informações contábeis que integrem os aspectos econômicos e financeiros da instituição; (iv) a falta de uma cultura organizacional para controle de custos nas instituições públicas; e (v) a falta de uma política que dê sustentação para a implantação do modelo.

Apesar do trecho citado trazer percalços discutidos em outras seções deste trabalho, inseriu-se para ressaltar como, na literatura, reiteram-se os recursos humanos ou a cultura organizacional como percalço importante no processo de implantação de sistemas de custos em hospitais.

A Figura 4 a seguir, resume os desafios relativos às questões relacionadas a gestão de custos. 
Desafios no Desenvolvimento e na Implantação de Sistemas de Custos em Hospitais Universitários Brasileiros

Márcio Luiz Borinelli, Welington Rocha, Diogo Moreira Carneiro, Alexandre dos Santos Silva

\begin{tabular}{|c|c|c|c|}
\hline & Desafios & Características & Ações \\
\hline 1 & $\begin{array}{c}\text { Desenvolver um sistema } \\
\text { de custos para um } \\
\text { conjunto de hospitais- } \\
\text { ensino }\end{array}$ & $\begin{array}{l}\text { Processos no segmento de } \\
\text { saúde caracterizados por } \\
\text { intensiva utilização de mão de } \\
\text { obra especializada, instalações e } \\
\text { equipamentos específicos e de } \\
\text { alto custo; predominância de } \\
\text { custos indiretos. }\end{array}$ & $\begin{array}{l}\text { Metodologia de custeio com } \\
\text { identificação dos direcionadores de } \\
\text { custos que representassem (i) uma } \\
\text { relação de causa e efeito entre sua } \\
\text { ocorrência e o consumo de recursos e } \\
\text { (ii) pudessem ser mensurados de } \\
\text { forma objetiva sistematicamente. }\end{array}$ \\
\hline 2 & $\begin{array}{l}\text { Os hospitais ofertam } \\
\text { produtos e serviços de } \\
\text { diversas naturezas }\end{array}$ & $\begin{array}{l}\text { Realização de serviços } \\
\text { específicos relacionados à } \\
\text { atenção à saúde, de hotelaria, } \\
\text { refeições etc.; utilização de } \\
\text { produtos por meio direto ou por } \\
\text { meio de consignação (órteses e } \\
\text { próteses). }\end{array}$ & $\begin{array}{l}\text { Conceber um modelo de custeamento } \\
\text { (i) capaz de refletir as relações entre } \\
\text { as entidades que compõem os custos } \\
\text { hospitalares e (ii) permitir a } \\
\text { associação de todos os custos aos } \\
\text { serviços ofertados pelos hospitais, (iii) } \\
\text { visando uma comparação ao } \\
\text { faturamento obtido por tipo de objeto } \\
\text { de custeio, particularmente no que diz } \\
\text { respeito aos procedimentos. }\end{array}$ \\
\hline 3 & $\begin{array}{l}\text { Amplitude da amostra } \\
\text { em termos de região } \\
\text { geográfica e } \\
\text { diversificação das } \\
\text { unidades }\end{array}$ & $\begin{array}{c}\text { Unidades hospitalares variam em } \\
\text { termos de porte (pequeno a } \\
\text { grande), grau de complexidade } \\
\text { (baixo a alto), nível de } \\
\text { especificidade (apenas uma } \\
\text { especialidade até aquelas que } \\
\text { ofertam múltiplas especialidades } \\
\text { da medicina). }\end{array}$ & $\begin{array}{l}\text { Conceber um sistema de custos que } \\
\text { atenda com a máxima precisão } \\
\text { possível a pluralidade das entidades } \\
\text { objeto de custeio e as necessidades } \\
\text { informacionais dos diversos gestores } \\
\text { e usuários. }\end{array}$ \\
\hline 4 & $\begin{array}{l}\text { Diferenças nos } \\
\text { processos e forma de } \\
\text { trabalho de cada } \\
\text { unidade }\end{array}$ & $\begin{array}{c}\text { Diferenças significativas no } \\
\text { universo que deve ser } \\
\text { considerado para a concepção } \\
\text { das informações de custos para } \\
\text { gestão, em especial em termos } \\
\text { de rotinas, atividades e } \\
\text { processos. }\end{array}$ & $\begin{array}{l}\text { O modelo de custeio que considere } \\
\text { todas (ou a maioria) estas } \\
\text { especificações, com metodologia } \\
\text { fortemente amparada na segregação } \\
\text { por atividades e na utilização de } \\
\text { rigorosos direcionadores de custos. }\end{array}$ \\
\hline 5 & $\begin{array}{l}\text { Diferentes propósitos de } \\
\text { usos das informações } \\
\text { de custos }\end{array}$ & $\begin{array}{c}\text { Foram identificadas } \\
\text { necessidades de informações } \\
\text { pontuais para tomada de } \\
\text { decisões específicas até } \\
\text { informações recorrentes para } \\
\text { decisões de gestão sistemáticas. }\end{array}$ & $\begin{array}{c}\text { Coube à equipe de pesquisadores } \\
\text { definir a metodologia mais adequada } \\
\text { para atender aos diferentes e } \\
\text { principais propósitos identificados } \\
\text { pelos usuários. }\end{array}$ \\
\hline 6 & $\begin{array}{c}\text { Necessidade de } \\
\text { integração entre o } \\
\text { sistema de custos e o } \\
\text { sistema contábil } \\
\text { utilizado pelas entidades } \\
\text { públicas }\end{array}$ & $\begin{array}{l}\text { Exemplo do custo com } \\
\text { depreciação que em muitos dos } \\
\text { hospitais os registros } \\
\text { patrimoniais encontram-se } \\
\text { desatualizados, mas são } \\
\text { utilizados para o sistema } \\
\text { contábil. }\end{array}$ & $\begin{array}{l}\text { Utilizou-se a mesma base de dados } \\
\text { usada pelo sistema contábil para o } \\
\text { sistema de custos. }\end{array}$ \\
\hline
\end{tabular}

Figura 4. Desafios Relativos aos Aspectos de Gestão de Custos

Fonte: Elaborado pelos autores. 
Desafios no Desenvolvimento e na Implantação de Sistemas de Custos em Hospitais Universitários Brasileiros

Márcio Luiz Borinelli, Welington Rocha, Diogo Moreira Carneiro, Alexandre dos Santos Silva

\subsection{Características da Tecnologia de Informações}

Não se pode implantar um sistema de informações de custos sem contemplar a tecnologia de informação (TI), uma vez que a interação dos usuários com o sistema de custos ocorre por meio da plataforma tecnológica. TI é fator crítico de sucesso.

Todos os hospitais pesquisados optaram por desenvolver ou modificar internamente a solução tecnológica para o sistema de custos a partir de plataforma própria de gestão dos serviços de saúde já existente na maioria deles.

Os Enterprise Resource Planning (ERPs), também conhecidos como Planejamento de Recursos Empresariais ou Sistemas de Gestão Integrados, contemplam diversos módulos e, nos casos em estudo, já eram customizados para gestão dos hospitais, com foco nas áreas de atenção à saúde, principalmente atendimento aos pacientes. O sistema de custos seria, então, mais um módulo na plataforma, operando de maneira integrada com outros, sendo que alguns deveriam funcionar como fonte de dados para o correto funcionamento desse.

O desenvolvimento de um sistema de custos em plataforma própria poderia trazer benefícios do ponto de vista de adequação aos objetivos específicos e integração com os outros sistemas em funcionamento nos hospitais, facilitando sua implantação. No entanto, a decisão da maioria dos hospitais acabou revelando uma série de contratempos que dificultaram sobremaneira o sucesso do projeto.

O desenvolvimento de um sistema de custos desde o início requer conhecimento de soluções de $\mathrm{TI}$, além da disponibilidade de recursos para converter os atributos do modelo conceitual em requisitos técnicos para desenvolver o sistema em linguagem de programação funcional e com interface aos usuários.

A opção por desenvolvimento interno ou por adaptação esbarrou em um problema: a geral carência de recursos humanos, muitas vezes com dedicação de apenas um funcionário. Essa mão de obra mostrou-se insuficiente para concluir o projeto, em face das recorrentes alterações nas escalas de prioridades, frequentemente preterido em virtude de outras demandas, relacionadas a processos de atenção aos pacientes. Santos Junior, Freitas e Luciano (2005) identificaram que, de fato, um dos 
Desafios no Desenvolvimento e na Implantação de Sistemas de Custos em Hospitais Universitários Brasileiros

Márcio Luiz Borinelli, Welington Rocha, Diogo Moreira Carneiro, Alexandre dos Santos Silva

principais fatores inibidores da implantação de sistemas, de modo geral, e de custos, de modo particular, são os que dizem respeito à resistência de funcionários antigos frente às novas tecnologias, a falta de suporte técnico, a ausência de políticas de motivação ou recompensa que estimulasse os funcionários na adoção do sistema, a falta de treinamento intensivo e constante e a falta de envolvimento dos funcionários.

Para apresentar respostas mínimas à medida em que o sistema era desenvolvido, optou-se por oferecer informações parciais de custos por grupos de recursos. Em certo sentido, essa versão inicial do sistema foi como um Produto Mínimo Viável (PMV). O PMV é um conceito recente e por essa razão, ainda não possui contornos bem definidos e está se difundindo na área de tecnologia da informação. Rolo (2016, p. 12) explica que o PMV "consiste em testar a ideia, o conceito de um produto ou serviço e o respectivo modelo de negócio numa fase muito inicial do desenvolvimento do mesmo - pré-produção - de modo a que sejam gastos o mínimo de recursos possíveis, humanos e materiais". De acordo com o autor, o PMV não é um protótipo, pois "tem de cumprir todos os requisitos necessários para que esse possa ser testado de maneira correta, ou seja, as ideias principais têm de estar bem implícitas e tudo o que possa ser considerado desnecessário não deve estar incluído" (Rolo, 2016, p. 12-13).

Nesse sentido, o primeiro grupo de recursos escolhido foi materiais e medicamentos, uma vez que dependiam só de dados já existentes em módulos dos ERPs já utilizados (farmácia, dispensação e almoxarifado). Em seguida, optou-se por oferecer informações dos custos relacionados à força de trabalho, mediante integração com sistemas de gestão de pessoal. Por fim, o mesmo foi feito com todos os custos associados a contratos de fornecimento de recursos e serviços (energia elétrica, água, aluguéis etc.).

Muitos hospitais adotavam seus ERPs apenas parcialmente, de modo que os dados originados em outros módulos não se mostravam confiáveis para fins de alocação de custos. Sequer custos diretos poderiam ser apropriados, por falta de dados. À época da conclusão do projeto, apenas parte dos hospitais tinha instalado os 
Desafios no Desenvolvimento e na Implantação de Sistemas de Custos em Hospitais Universitários Brasileiros

Márcio Luiz Borinelli, Welington Rocha, Diogo Moreira Carneiro, Alexandre dos Santos Silva

módulos de farmácia, medicamentos e almoxarifado. Somente essas unidades, portanto, estavam aptas a operar o primeiro módulo do sistema de custos, relativo aos custos diretos com materiais e medicamentos.

Além disso, os módulos que dependiam de sistemas externos se mostraram ainda mais difíceis de implantar. A gestão de pessoal no funcionalismo público é algo peculiar, principalmente quando há cessão de funcionários entre órgãos.

A gestão de pessoal ocorre geralmente em sistemas centralizados, seja na esfera federal, estadual ou municipal. $O$ acesso aos dados dos custos de pessoal esbarra em intrincadas relações interdepartamentais dentro do governo, e a obtenção de dados requer procedimentos burocráticos complexos e integração com sistemas de terceiros.

Ademais, a pluralidade da natureza de vínculos nos hospitais, aspecto já mencionado, acrescida da miríade de rubricas sob as quais os funcionários públicos são remunerados, tornam o cálculo do custo da força de trabalho um desafio complexo e difícil de solucionar. Sua resolução passa por diversas ferramentas de integração que necessitam de manutenção permanente, em que muitas delas ensejam relacionamento com outras esferas de governo por meio de ofícios, protocolos e outros trâmites burocráticos.

Há que se considerar ainda as especificidades de cada caso concreto, pois os hospitais alcançam soluções locais para lidar com suas dificuldades. Nesse sentido, a prática de terceirização de trabalhadores à revelia do arcabouço legal, além da utilização de mão de obra ligada às universidades e fundações, são desafios adicionais para o desenvolvimento e a integração dos sistemas.

Por fim, a integração, no que diz respeito ao custo de outros recursos, também esbarrou em dificuldades, principalmente quanto à falta de processos bem definidos de registro e gestão de contratos de fornecimento de bens e serviços.

O que se notou, nesse aspecto, foi a necessidade de se desenvolver melhorias nos módulos ou sistemas existentes de forma que pudessem gerar os dados a serem tratados pelo sistema de custos. Exemplos disso são os sistemas de gestão de 
Desafios no Desenvolvimento e na Implantação de Sistemas de Custos em Hospitais Universitários Brasileiros

Márcio Luiz Borinelli, Welington Rocha, Diogo Moreira Carneiro, Alexandre dos Santos Silva

contratos, que mantêm registro dos contratos, mas não possuem os elementos necessários à operacionalização dos direcionadores de custos definidos no modelo conceitual. Apesar da predisposição das equipes de custos em providenciar as melhorias necessárias, isso sempre ficava condicionado a uma fila interminável de prioridades das áreas de $\mathrm{TI}$ dos hospitais.

Por conseguinte, os aspectos de TI ligados ao desenvolvimento e à implantação de plataformas tecnológicas para operacionalizar o sistema de custos constituiu o principal entrave ao sucesso do projeto, sendo o maior responsável pela protelação das entregas e da viabilização do modelo conceitual desenvolvido em praticamente todos os hospitais contemplados pelo projeto.

A síntese dos desafios relativos à TI é apresentada na Figura 5 a seguir. 
Desafios no Desenvolvimento e na Implantação de Sistemas de Custos em Hospitais

Universitários Brasileiros

Márcio Luiz Borinelli, Welington Rocha, Diogo Moreira Carneiro, Alexandre dos Santos Silva

\begin{tabular}{|c|c|c|c|}
\hline & Desafios & Características & Ações \\
\hline 1 & $\begin{array}{l}\text { Disponibilidade de } \\
\text { recursos (pessoal) com } \\
\text { adequado } \\
\text { conhecimento em } \\
\text { soluções de TI }\end{array}$ & $\begin{array}{l}\text { O grupo de hospitais-ensino } \\
\text { investigados conta com ótimos } \\
\text { quadros; adota práticas modernas de } \\
\text { desenvolvimento de software; o } \\
\text { desenvolvimento do sistema, por } \\
\text { opção dos escalões superiores, } \\
\text { contou com a dedicação parcial de } \\
\text { apenas um funcionário, muito } \\
\text { capacitado, mas que não tinha } \\
\text { dedicação suficiente ao projeto. }\end{array}$ & $\begin{array}{l}\text { Apresentar soluções mínimas e } \\
\text { parciais na medida em que o } \\
\text { sistema estava sendo } \\
\text { desenvolvido, com informações de } \\
\text { custos segregadas por grupo de } \\
\text { recursos: (i) materiais e } \\
\text { medicamentos; (ii) força de } \\
\text { trabalho; (iii) todos os outros } \\
\text { custos associados a contratos de } \\
\text { fornecimento. }\end{array}$ \\
\hline 2 & $\begin{array}{l}\text { Integração com outros } \\
\text { sistemas internos e } \\
\text { outros módulos do ERP }\end{array}$ & $\begin{array}{c}\text { Hospitais que adotavam o ERP } \\
\text { parcialmente; somente parte dos } \\
\text { hospitais tinham instalado os } \\
\text { módulos de farmácia, medicamentos } \\
\text { e almoxarifado. }\end{array}$ & $\begin{array}{c}\text { Iniciar a implementação pelos } \\
\text { hospitais que tinham tais módulos } \\
\text { e recomendar à gestão a } \\
\text { priorização desses módulos nos } \\
\text { demais hospitais que faziam parte } \\
\text { do projeto. } \\
\end{array}$ \\
\hline 3 & $\begin{array}{l}\text { Integração com outros } \\
\text { sistemas externos }\end{array}$ & $\begin{array}{l}\text { Há custos que dependiam de } \\
\text { sistemas externos, uma vez que há } \\
\text { cessão de pessoal entre diversos } \\
\text { órgãos públicos; a gestão de pessoal } \\
\text { em sistemas centralizados sob }\end{array}$ & \multirow{3}{*}{$\begin{array}{l}\text { Estabelecimento de parcerias para } \\
\text { obtenção dos dados por meio de } \\
\text { ferramentas de integração que } \\
\text { necessitam de manutenção } \\
\text { permanente. }\end{array}$} \\
\hline 4 & $\begin{array}{l}\text { Pluralidade de vínculos } \\
\text { existentes nos hospitais }\end{array}$ & $\begin{array}{c}\text { Diferentes rubricas sob as quais os } \\
\text { funcionários públicos são } \\
\text { remunerados. }\end{array}$ & \\
\hline 5 & $\begin{array}{c}\text { Particularidades } \\
\text { específicas dos } \\
\text { hospitais em termos de } \\
\text { pessoal utilizado } \\
\end{array}$ & $\begin{array}{l}\text { Utilização de mão de obra } \\
\text { terceirizada e de mão de obra ligada } \\
\text { a universidade e fundações. }\end{array}$ & \\
\hline 6 & $\begin{array}{l}\text { Obtenção de dados } \\
\text { relativos a "outros } \\
\text { custos" }\end{array}$ & $\begin{array}{c}\text { Falta de processos em registro e } \\
\text { gestão de contratos de fornecimento } \\
\text { pelos hospitais. }\end{array}$ & $\begin{array}{c}\text { Desenvolver preliminarmente } \\
\text { melhorias nos módulos ou } \\
\text { sistemas existentes que possam } \\
\text { gerar dados a serem tratados pelo } \\
\text { sistema de custos (ex. sistema de } \\
\text { contratos). }\end{array}$ \\
\hline
\end{tabular}

Figura 5. Desafios relativos às características de tecnologias de informações

Fonte: Elaborado pelos autores.

\section{CONSIDERAÇÕES FINAIS}

Os desafios, entraves e percalços identificados na concepção, desenvolvimento e implantação do sistema de apuração de custos para hospitais universitários brasileiros resumem-se em cinco categorias:

a) Características organizacionais e do processo gestão. Diferentes estruturas 
Desafios no Desenvolvimento e na Implantação de Sistemas de Custos em Hospitais Universitários Brasileiros

Márcio Luiz Borinelli, Welington Rocha, Diogo Moreira Carneiro, Alexandre dos Santos Silva

organizacionais (organogramas), compartilhamento de recursos materiais e humanos entre hospitais e suas respectivas universidades, diversidade de processos, diferentes níveis de qualidade dos sistemas de controles internos, rotação de pessoal e alternância de dirigentes;

b) Aspectos legais e normativos inerentes ao setor público. Rigidez das normas relativas aos processos de licitação, dificuldades para aquisição de bens e serviços complementares ao sistema de custos;

c) Diversidade de porte e de níveis de complexidade. Hospitais de pequeno e de médio porte; hospitais de baixa e de alta complexidade etc.;

d) Diversidade de objetos de custeio e de propósitos de uso das informações. Tendência de médicos gestores a pretender custear quase tudo, de atendimento ambulatorial a procedimentos cirúrgicos por diferentes equipes médicas;

e) Escala de prioridades das áreas de tecnologia de informação. Dada a carência dos hospitais quanto a sistemas para gestão de assistência à saúde, o sistema de custos foi sucessivamente postergado.

A identificação das causas dos diversos desafios e percalços relatados neste trabalho e as respostas encontradas podem ampliar o conhecimento sobre o tema, qual seja, gestão hospitalar, fazendo avançar o conhecimento, além de subsidiar profissionais envolvidos em projetos dessa natureza a se antecipar em relação a esses desafios, empecilhos e dificuldades.

O trabalho evidenciou que o sistema de custos foi concebido e desenvolvido, porém a implantação não ocorreu tendo em vista o conjunto de elementos analisados neste trabalho. Dessa maneira, entende-se que os achados desta pesquisa podem permitir que outros pesquisadores e profissionais da área se aprofundem nesses elementos quando do desenvolvimento de seus projetos de tal forma a evitarem o insucesso dos mesmos.

Do ponto de vista dos hospitais universitários, qualquer hospital que conseguisse superar esses empecilhos e implantar um sistema de custos integrado, capaz de 
Desafios no Desenvolvimento e na Implantação de Sistemas de Custos em Hospitais Universitários Brasileiros

Márcio Luiz Borinelli, Welington Rocha, Diogo Moreira Carneiro, Alexandre dos Santos Silva

fornecer informações confiáveis, estaria munido de ferramentas suficientes para: tomar decisões de gestão com acurácia; questionar a tabela SUS de preços com base nos custos incorridas pela entidade; possuir um modelo de gestão que não estivesse à mercê da conjuntura política; possuir informações comparáveis ao longo do tempo, o que permitiria o desenvolvimento de estratégias para redução de custos ou ampliação de investimentos; tornaria possível aos hospitais contratualizarem metas de atendimento realistas junto ao SUS; e talvez até tornasse possível a separação da gestão hospitalar, da gestão universitária.

No caso específico dos hospitais universitários federais, sugere-se como tema para pesquisas futuras a tentativa de implantação de sistemas de custos de modo regional, a fim de verificar se, diante de um locus mais restrito, é possível dirimir algumas das disparidades identificadas neste estudo.

Pode-se considerar também que inúmeros aspectos aqui apresentados como parte de um todo podem ser extensamente abordados a título de se pensar soluções definitivas para problemas antigos; por exemplo, como melhorar processos de licitação no setor público; tornar a tecnologia de informação um recurso mais difundido no setor público; padronizar os diferentes regimes jurídicos de contratação que uma entidade pública pode utilizar etc.

\section{REFERÊNCIAS}

Abbeele, A. van den., Roodhooft, F., \& Warlop, L. (2009). The effect of cost information on buyer - supplier negotiations in different power settings. Accounting, Organizations and Society, 34(2), 245-266. DOI: https://doi.org/10.1016/j.aos.2008.05.005

Atkinson, A. A., Balakrishnan, R., Booth, P., Cote, J. M., Groot, T., Malmi, T., Roberts, H., Uliana, E. \& Wu, A. (1997). New directions in management accounting research. Journal of Management Accounting Research, 9, 79-108.

Barros, C. da C., Silva, J. D. G. da., Souza, F. J. V. de., Melo, M. M. D. de., \& Taveira, L. B. (2013). Há sistemas de custos nos hospitais universitários federais? Revista de Estudos Contábeis, 4(6), 78-98, jan./jun. 
Bertó, D. J., \& Beulke, R. (2012). Gestão de custos e resultados na saúde: Hospitais. Clínicas, Laboratórios e Congêneres. (5a ed.). São Paulo: Saraiva.

Bonacim, C. A. G., \& Araujo, A. M. P. de. (2010). Gestão de custos aplicada a hospitais universitários públicos: a experiência do Hospital das Clínicas da Faculdade de Medicina de Ribeirão Preto da USP. Revista de Administração Pública, 44(4), 903931, jul./ago.

Boyd, L. H., \& Cox, J. F. (2002). Optimal decision making using cost accounting information. International Journal of Production Research, 40(8), 1879-1898. DOI: DOI: $10.1080 / 00207540210122239$

Costa, J. A., \& Miranda, C. R. de F. (2002). ACP - Apropriação de Custos Públicos: metodologia e projeto. Secretaria da Fazenda do Estado da Bahia, Salvador, BA, Brasil. Recuperado de: http://www.sefaz.ba.gov.br/administracao/acp_metodologia_projeto.pdf

Cruz, C. S. da., Andrade, E. L. P. de., \& Figueiredo, R. M. da C. (2011). Processo de Contratação de Serviços de Tecnologia da Informação para Organizações Públicas. Brasília: Ministério da Ciência e Tecnologia.

Decreto $\mathrm{n}^{\circ}$ 7.082, de 27 de janeiro de 2010. (2010, 27 de janeiro). Recuperado de: http://www.planalto.gov.br/ccivil_03/_ato2007-2010/2010/decreto/d7082.htm

Devine, K.; Ealey, T., \& Clock, P. O. (2008). A Framework for Cost Management and Decision Support Across Health Care Organizations of Varying Size and Scope. Journal of Health Care Finance, 35(2), 63-75.

Gil, A. C. (1991). Como elaborar projetos de pesquisa. (3a ed.). São Paulo: Atlas.

Holanda, V. B., \& Machado, N. (2010). Diretrizes e modelo conceitual de custos para o setor público a partir da experiência no governo federal do Brasil. Revista de Administração Pública, 44(4), 791-820.

Horngren, C. T., Sundem, G. L., \& Stratton, W. O. (2008). Sistemas de gestão de custos e custeio baseado em atividades. São Paulo: Pearson Prentice Hall.

Hughes, S., \& Gjerde, K. P. (2003). Do Different Cost Systems Make a Difference? Management Accounting Quarterly, 22-30.

Jerico, M., \& Castilho, V. (2004). Treinamento e desenvolvimento de pessoal de enfermagem: um modelo de planilha de custos. Revista da Escola de Enfermagem da USP, 38(3), 326-331. DOI: https://doi.org/10.1590/S0080-62342004000300011 
Desafios no Desenvolvimento e na Implantação de Sistemas de Custos em Hospitais Universitários Brasileiros

Márcio Luiz Borinelli, Welington Rocha, Diogo Moreira Carneiro, Alexandre dos Santos Silva

Johnson, H. T., \& Kaplan, R. S. (1991). Relevance lost: The rise and fall of management accounting. Boston, Mass: Harvard Business School Press.

Kaplan, R. S. (1988). One cost system isn't enough - Are managers getting the information they need to value inventory, control operations, and measure product costs? Harvard Business Review, 66, 61-66.

Kirche, E., \& Srivastava, R. (2005). An ABC-based cost model with inventory and order level costs: A comparison with TOC. International Journal of Production Research, 43(8), 1685-1710. DOI: 10.1080/002075412331317836

Lei $\mathrm{n}^{\circ}$ 8.080, de 19 de setembro de 1990. (1990, 19 de setembro). Recuperado de: http://www.planalto.gov.br/ccivil_03/leis/L8080.htm

Lukka, K., \& Granlund, M. (1996). Cost accounting in Finland: current practice and trends of development. European Accounting Review, 5(1), 1-28. DOI: $10.1080 / 09638189600000001$

Machado, N. (2002). Sistema de informação de custo: diretrizes para integração ao orçamento público e à contabilidade governamental (Tese de doutorado). Faculdade de Economia, Administração e Contabilidade, Universidade de São Paulo, São Paulo, SP, Brasil.

Martins, E. (2018). Contabilidade de custos. (11a ed.). São Paulo: Atlas.

Martins, E., \& Rocha, W. (2015). Métodos de custeio comparados: custos e margens analisados sob diferentes perspectivas. (2a ed.). São Paulo: Atlas.

Ministério da Educação. (n.d.). Hospitais Universitários. Recuperado de: http://portal.mec.gov.br/index.php?ltemid=512\&id=12267\&option=com_content\&vie $\mathrm{w}=$ article

Mugnol, K. C., \& Ferraz, M. B. (2006). Sistema de informação como ferramenta de cálculo e gestão de custos em laboratórios de análises clínicas. Jornal Brasileiro de Patologia e Medicina Laboratorial, 42(2), 95-102. DOI: http://dx.doi.org/10.1590/S1676-24442006000200006

Oliveira, A. G. de., Blanski, M. B. S., \& Silva, C. L. da. (2015). Gestão de Custos como Instrumentos de Governança Pública: um modelo de custeio para os hospitais públicos. XIV Congresso Internacional de Costos, Colombia. Recuperado de: https://intercostos.org/documentos/congreso-14/70.pdf

Oliveira, D. F. (2016). A implantação de um sistema de gestão de custos no hospital 
Desafios no Desenvolvimento e na Implantação de Sistemas de Custos em Hospitais Universitários Brasileiros

Márcio Luiz Borinelli, Welington Rocha, Diogo Moreira Carneiro, Alexandre dos Santos Silva

universitário pela Ebserh: um estudo de caso com utilização do PMBOK. Revista de Administração Hospitalar e Inovação em Saúde, 13 (3), 122-139. DOI: https://doi.org/10.21450/rahis.v13i3.3172

Pinzan, A. F. (2013). Métodos de custeio e seus propósitos de uso: Análise por meio de estudos de casos múltiplos. (Dissertação de mestrado). Faculdade de Economia, Administração e Contabilidade, Universidade de São Paulo, São Paulo, SP, Brasil.

Portaria Interministerial $n^{\circ} 883$, de 5 de julho de 2010. (2010, 5 de julho). Recuperado de:

http://www2.ebserh.gov.br/documents/15796/65717/portaria_rehuf.pdf/43686833d346-489d-ab13-4a3a6b9cd075

Rolo, V. D. B. (2016). Produto Mínimo Viável para Jogos Digitais. (Dissertação de mestrado). Faculdade de Design e Desenvolvimento de Jogos Digitais, Universidade da Beira Interior, Covilhã, Portugual.

Roy, R.; Souchoroukov, P., \& Griggs, T. (2008). Function-based cost estimating. International Journal of Production Research, 46(10), 2621-2650. DOI: ff10.1080/00207540601094440

Santos Junior, S., Freitas, H., \& Luciano, E. M. (2005). Dificuldades para o Uso da Tecnologia da Informação. Revista de Administração de Empresas, 4(2), jul./dez.

Sarturi, C. A. (2013). Os modelos de Administração Pública: patrimonialista, burocrática e gerencial, Conteúdo Jurídico. Recuperado de: http://www.conteudojuridico.com.br/?artigos\&ver=2.43523\&seo $=1$

Silva, R. A. G. da., Oliveira, D. F., Campos, A., \& Oliveira, E. C. de. (2015). Implementação do sistema de custos no Hospital Universitário Professor Alberto Antunes pela Empresa Brasileira de Serviços Hospitalares - Ebserh. XXII Congresso Brasileiro de Custos. Recuperado de: https://anaiscbc.emnuvens.com.br/anais/article/view/3968

Sodré, F., Littike, D., Drago, L. M. B., \& Perim, M. C. M. (2013). Empresa Brasileira de Serviços Hospitalares: um novo modelo de gestão. Serviço Social \& Sociedade, 114, 365-380, abr./jun. DOI: https://doi.org/10.1590/S0101-66282013000200009

Souza, P. C., \& Scatena, J. H. G. (2009). Implantação de Sistema de Gestão de Custos em Hospitais Públicos. Revista Qualitas, 9(3), 1-11.

Toigo, L. A., \& Nascimento, A. M. (2008). Contribuições dos sistemas de informações integrados para a contabilidade. Revista de Informação Contábil, 2(3), 90-110. 
Desafios no Desenvolvimento e na Implantação de Sistemas de Custos em Hospitais Universitários Brasileiros

Márcio Luiz Borinelli, Welington Rocha, Diogo Moreira Carneiro, Alexandre dos Santos Silva

Torres, M. D. de F. (2004). Estado, democracia e administração pública no Brasil. Rio de Janeiro: Editora FGV.

Waller, W. S., Shapiro, B., \& Sevcik, G. (1999). Do cost-based pricing biases persist in laboratory markets? Accounting, Organizations.

\section{AGRADECIMENTO}

Os autores agradecem a pesquisadora Patricia Righetto, mestranda em Gestão de Políticas Públicas pela Escola de Artes, Ciências e Humanidades da Universidade de São Paulo (EACH-USP), pela relevante contribuição na revisão final deste artigo.

Data de Submissão: 02/06/2020

Data de Aceite: 30/12/2020 